\title{
REDES DE INFRAESTRUTURAS E A INTEGRAÇÃO REGIONAL NA AMÉRICA DO SUL: PROJETOS, CONTRADIÇÕES E INTENCIONALIDADES
}

\author{
INFRASTRUCTURE NETWORKS AND REGIONAL INTEGRATION IN SOUTH AMERICA: PROJECTS, CONTRADICTIONS \\ AND INTENTIONALITIES
}

\section{RESUMO}

As redes técnicas de infraestruturas são fundamentais para compreender as novas dinâmicas territoriais e o duplo movimento de integração e desintegração, fruto das contradições da fase atual do capitalismo flexível. O objetivo deste artigo é refletir sobre o papel dos projetos de integração regional na América do Sul, elaborados no âmbito do COSIPLAN/IIRSA para a expansão das redes de infraestruturas de transportes, considerando a demanda de circulação e acumulação de capital, bem como os entraves para a execução desses projetos.

Palavras-chave: Redes; Integração regional; América do Sul; COSIPLAN/IIRSA; Eixo de Capricórnio.

\section{ABSTRACT}

The technical infrastructure networks are fundamental to understand the new territorial dynamics and the double movement of integration and disintegration, fruit of the contradictions of the current phase of flexible capitalism. The objective of this article is to reflect on the role of the regional integration projects in South America, elaborated in the scope of COSIPLAN/IIRSA for the expansion of transport infrastructures networks, considering the demand of circulation and accumulation of capital, as well as the obstacles for the execution of these projects.

Keywords: Networks; Regional integration; South America; COSIPLAN/IIRSA; Capricorn Hub.
Dayana Aparecida Marques Oliveira Cruz ${ }^{\text {a }}$

${ }^{a}$ Universidade Federal de São Carlos (UFSCAR), São Carlos, SP, Brasil

DOI: $10.12957 /$ geouerj.2020.45553

Correpondência: d.dayana@hotmail.com

Recebido em: 25 ago. 2019

Revisado em: 22 abr. 2020

Aceito em: 4 jun.2020 


\section{INTRODUÇÃO}

No atual período do capitalismo flexível, a compressão espaço-tempo, a multiplicidade de redes e aumento da velocidade dos fluxos têm sido aprimorada a partir das dinâmicas territoriais. Elas são ocasionadas pelos frutos da revolução científico-tecnológica, sendo, portanto, decorrentes do processo de desenvolvimento do modo de produção vigente.

Neste contexto, observamos o duplo movimento de integração-desintegração dos territórios nacionais e subcontinentais promovidos pela expansão das redes técnicas no território, feita de forma seletiva e desigual, com a finalidade específica de contribuir para o processo de acumulação e circulação de capital.

A complexidade do duplo movimento de integração-desintegração se dá pela ação dos múltiplos agentes responsáveis pela criação de demandas de expansão das redes de infraestruturas, por aqueles que projetam e gerenciam essas redes, e pelos que reivindicam o acesso a elas e questionam sua finalidade.

Projetos de expansão das redes de infraestruturas para a integração na América do Sul trazem à tona discussões sobre o contexto político e econômico regional, sobretudo, por conta da condição periférica dos países do subcontinente e de sua posição ocupada na divisão territorial do trabalho, da desigualdade característica dos territórios nacionais, da escassez de investimentos financeiros para garantir a incorporação de novos conteúdos técnicos nos fixos do território.

Neste artigo, adotamos como recorte para elucidar essa discussão, os projetos propostos pelo Conselho Sul-americano de Infraestrutura e Planejamento/Iniciativa para a Integração Regional Sul-americana (COSIPLAN/IIRSA). O objetivo deste artigo é refletir sobre o papel deles no fomento da integração regional na América do Sul, considerando a demanda de circulação e acumulação de capital, bem como os entraves para a execução desses projetos. Para tanto, incluímos uma revisão bibliográfica sobre as redes geográficas e a integração regional, que são suporte à análise do levantamento de dados relacionados ao Eixo de Capricórnio do COSIPLAN/IIRSA.

\section{Dinâmicas territoriais, redes e integração regional sul-americana no início do século XXI}

De acordo com Egler (2014), a virada do século XXI propiciou o surgimento de um novo perfil de integração na América do Sul, marcado pela redefinição dos papéis dos estados nacionais, expansão das redes globais, multiplicidade e aumento da velocidade dos fluxos. O motor para o surgimento deste novo perfil foi impulsionado pelos novos rumos políticos e econômicos do subcontinente, que iniciou uma fase de aprofundamento da cooperação econômica e estímulo à integração regional. 
Observa-se, portanto, um duplo movimento de globalização e regionalização. De acordo com Arroyo (2002), ambos os processos resultaram das transformações estruturais de reordenação do cenário global, cuja sobreposição de redes e de conflito da atuação de múltiplos agentes (empresas multinacionais, capital estrangeiro, estados nacionais, acordos multilaterais, sociedade civil organizada etc.) tornou as dinâmicas territoriais ainda mais complexas.

As dinâmicas territoriais complexas aqui mencionadas associam-se diretamente à relação dialética entre fixos e fluxos e suas implicações nos territórios. Fixos e fluxos possuem maior dinamismo no período contemporâneo por conta do conteúdo técnico do território, conteúdo este que é propagado de forma seletiva e desigual de acordo com as exigências de circulação para a acumulação capitalista (SANTOS, 2008).

A seletividade incide sobre as interações espaciais. Se o emprego das técnicas no território é desigual, a concentração e polarização das interações espaciais são inevitáveis. As interações espaciais constituem um movimento amplo pelo espaço, com intensidades, direções, frequências e ocorrências de acordo com os propósitos do movimento (CORRÊA, 1997), resultando em transformações nas formações materiais que interagem.

As interações vão além do deslocamento, elas estão ligadas às relações econômicas, políticas e sociais presentes no que Lefebvre (2001) chama de ordem próxima e ordem distante. Elas necessitam de uma base material para que possam se efetivar, a configuração desta base é seletiva, fruto da reprodução e transformação social, e da divisão territorial do trabalho. Por outro lado, a base material determina as condições de circulação para a acumulação de capital, relacionadas às interações assimétricas na sociedade capitalista.

A seletividade não é exclusiva do período atual. Ela ocorre em diferentes tempos, implica em rugosidades que coexistem com as novas técnicas (SANTOS, 2008) e valoriza diferencialmente os territórios (BECKER, 2000).

Os projetos de integração regional são exemplos dessa dinâmica. Eles propõem a incorporação de um novo conteúdo técnico no território que se sobrepõem ao conteúdo técnico anterior. Os novos conteúdos técnicos possuem como intencionalidade a promoção da fluidez territorial, a partir do incremento da rede de infraestruturas. Esse incremento prioriza a circulação e exportação de commodities para os países do centro do sistema capitalista, em especial, os asiáticos, reforçando o papel dos países sul-americanos na divisão territorial do trabalho.

A coexistência de técnicas de diferentes tempos ajuda a compreender as transformações do espaço geográfico e suas formas de produção, consumo e apropriação, pois "a técnica é tempo congelado e revela uma história" (SANTOS, 2008, p. 48). Ela compõe a materialidade das interações espaciais em forma de redes 
geográficas que são "como qualquer materialidade social, produtos e condições sociais" (CORRÊA, 2001, p. 109).

Na América do Sul, as rugosidades demonstram, dentre outras coisas: o passado de exploração colonial dos recursos naturais, a ocupação territorial concentrada, as marcas da escravidão e da exploração da força de trabalho, os efeitos da industrialização tardia, as dinâmicas populacionais de migração, a acumulação de capital nas metrópoles, a atuação das empresas de capital estrangeiro, a relação econômica e política desigual com os países do centro do sistema capitalista.

Todos esses aspectos foram acompanhados de conteúdos técnicos, heranças que compõem a configuração territorial contemporânea. No caso sul-americano, ela é materializada pela existência de uma rede de infraestruturas concentrada, limitada, deteriorada, com poucas conexões ou capacidade para atender os fluxos de mercadorias e pessoas.

Por outro lado, novos conteúdos técnicos são incorporados rapidamente a partir de uma relação complexa entre diferentes escalas, de tensão entre homogeneização e resistência, de verticalidades... Sob a égide do capitalismo flexível, o espaço reticulado contemporâneo tem em sua essência as marcas dessas contradições, que trouxeram profundas mudanças políticas, sociais e territoriais, encabeçadas pela nova economia do último quartel do século XX, período denominado por Santos (2008) como meio técnicocientífico-informacional. Castells (1999) ao analisar as transformações econômicas do último quartel do século XX, indica três características básicas da organização de uma nova economia, que é: informacional, global e em rede. Sua base são as inovações tecnológicas, ou seja, os conteúdos técnicos característicos do período atual.

A espacialização dos conteúdos técnicos geram tensões entre a homogeneização e as resistências em um complexo território-rede (HAESBAERT, 2004). Destacam-se as pautas ambientais, a luta pelos direitos das populações originárias, e o questionamento da finalidade de execução dos projetos de infraestruturas.

Dessa forma, as condições de vida, as tentativas de homogeneização das culturas e costumes, e os impactos ambientais são importantes gatilhos que motivam os excluídos a exercer, de forma organizada, uma pressão sobre as forças produtivas dominantes. A contraposição de forças e a complexidade do território-rede trás à tona, discussões sobre os projetos de integração regional, a intencionalidade e desdobramentos territoriais das tentativas de implantação de novas redes técnicas, e suas articulações inter-escalares.

Neste sentido, embora os projetos objetivem a integração territorial, os sujeitos que não estão incluídos como beneficiários diretos das redes técnicas sentem-se cada vez mais excluídos. Assim, integração e desintegração são dois lados de uma mesma moeda. 
Dias (2000) observa a simultaneidade das tendências de integração (produtiva, de mercado, financeira etc.) e desintegração (exclusão), permeadas pelas relações de poder que são determinantes para as conexões da rede. Em outras palavras "a intensificação da circulação interagindo com as novas formas de organização da produção imprime simultaneamente ordem à desordem, numa perspectiva essencialmente geográfica" (DIAS, 2000, p. 154).

As relações de poder contidas na capacidade de ordenar e desordenar as redes foram observadas também por Raffestin (1993). Para ele, as redes de circulação e comunicação estão relacionadas às transformações espaço-temporais, elas servem como estratégias para dominar o território.

A busca pelo domínio do território existe em todas as escalas e é feita por múltiplos agentes: corporações transnacionais, grandes bancos, sociedade civil organizada, ONGs, Estado nacional etc. Aqueles que detêm o capital possuem vantagens por possuírem os recursos financeiros para a ampliação das redes técnicas de circulação e comunicação, além de estarem associados de forma política e ideológica com os representantes do Estado capitalista - detentor do papel central no planejamento, execução e gestão dos projetos de infraestruturas de circulação e comunicação (ARROYO, 2015).

\section{A IIRSA e a UNASUL}

Sob o resquício do regionalismo aberto e no contexto regido pelas políticas neoliberais foi criada a Iniciativa para a Integração Regional Sul-americana (IIRSA), em 2000, na cidade de Brasília. A iniciativa teve como principal objetivo a promoção da integração econômica e territorial sul-americana, através da modernização do conteúdo técnico das redes de infraestruturas de transportes, energia e comunicações, visando articular diferentes mercados.

De acordo com Porto-Gonçalves e Quental (2015) e Albuquerque (2015), existe uma estreita relação entre a proposta de integração geopolítica e econômica brasileira à proposta da IIRSA. Os Eixos de Integração e Desenvolvimento (EIDs) foram baseados na experiência brasileira de Eixos Nacionais de Integração e Desenvolvimento (ENID), que fizeram parte do programa "Brasil em Ação" (1996-1999) e do programa "Avança Brasil", derivado do "Plano Plurianual de Investimentos" (2000/2003) (SOUZA, 2011).

A criação destes Eixos de Integração tinha por principais objetivos: a construção de um sistema integrado de logística capaz de promover a competitividade dos produtos brasileiros; a incorporação de novas áreas do país à dinâmica do comércio global; e a consolidação da hegemonia política e econômica do Brasil na América do Sul. (PORTO GONÇALVES e QUENTAL, 2012, p. 13).

Castillo (2011) critica a forma como esses eixos foram conduzidos. Para ele, os ENIDs substituíram o planejamento estratégico ao serem impostos como a solução para alavancar o desenvolvimento brasileiro por 
meio do investimento em corredores de transportes, com o objetivo principal de diminuir o custo na circulação de commodities para exportação (CASTILLO, 2011). Outra crítica feita por Porto Gonçalves e Quental (2012), é a proposição de eixos considerando as áreas agrupadas como vazios demográficos, sendo a biodiversidade e a diversidade das populações um obstáculo a ser superado.

Já Albuquerque (2015) ressalta que no contexto geopolítico, o planejamento das infraestruturas de transportes terrestres da IIRSA assemelha-se à proposta de Travassos - geopolítico brasileiro do início do século XX. Para Travassos, era preciso expandir a rede de transportes terrestres a fim de propiciar a interlocução das redes do Brasil com o triângulo geopolítico sul-americano boliviano. Essa expansão neutralizaria a influência argentina da época e seria responsável pelo domínio brasileiro no subcontinente. A relação que Albuquerque (2015) estabelece entre a proposta dos EIDs e a proposta de Travassos está no trajeto das redes, cuja semelhança remonta à necessidade pretérita de expansão das infraestruturas. Além disso, existe uma dimensão política na execução de projetos de infraestruturas no subcontinente, discutida com maior profundidade por Oliveira Cruz (2017).

Com a transformação no quadro político e econômico na América do Sul, a partir de 2003, liderada pela ascenção do governo de Luiz Inácio Lula da Silva, no Brasil, a IIRSA continuou atuante, porém novas questões passaram a ganhar destaque no cenário regional, envolvendo outros focos de promoção da integração regional, que iam além do debate sobre as redes de infraestruturas.

Como resultado deste novo contexto, foi criada a União das Nações Sul-americanas (UNASUL) em 2008, que em 2011 passou a vigorar como personalidade jurídica regional. Um dos objetivos da iniciativa de integração é o fortalecimento da autonomia e soberania dos países membros.

A criação da UNASUL não teve como objetivo a formulação de uma política externa comum, mas a superação das diferenças, mantendo um espaço de interlocução, com foco para proposições na escala sulamericana, a fim de criar consensos (VIGEVANI e RAMANZINI JÚNIOR, 2014).

Ao invés de continuar sendo um acordo independente, a IIRSA foi incorporada em um dos oito conselhos ministeriais da UNASUL, o Conselho Sul-americano de Infraestrutura e Planejamento (COSIPLAN), que passou a ser denominado em 2011 como COSIPLAN/IIRSA. Os conselhos ministeriais da UNASUL buscam fomentar o diálogo regional sobre a integração e a cooperação em diversos campos, diferente das iniciativas anteriores, cujo foco era a integração comercial (LIMA, 2008) ou apenas a integração territorial, como no caso da antiga IIRSA.

Enquanto ideologicamente houve uma mudança na condução da integração regional sul-americana, na prática, a organização do COSIPLAN/IIRSA permaneceu similar à IIRSA. O que mudou foi a promoção de fóruns, 
nos quais os países passaram a discutir aspectos pertinentes relacionados aos projetos (trajetos, investimento, adaptações, etc.).

A proposta do COSIPLAN/IIRSA é a regionalização da América do Sul em Eixos de Integração e Desenvolvimento (EIDs), a saber: Andino; Amazonas; Capricórnio; Escudo Guianês; Hidrovia Paraguai - Paraná; Interoceânico Central; MERCOSUL-Chile; Peru-Brasil-Bolívia; Do Sul.

A figura 1 mostra a delimitação de cada um dos eixos do COSIPLAN/IIRSA. Vale ressaltar que os eixos se sobrepõem e que mais de um país integra diferentes eixos porque a delimitação é feita a partir de objetivos específicos que definem o perfil dos projetos.

Figura 1. Eixos de Integração e Desenvolvimento. Fonte: COSIPLAN, 2019, adaptado pela autora

Andino
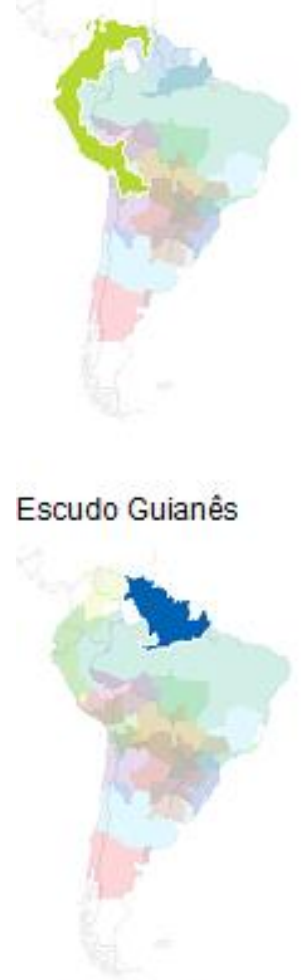

MERCOSUL-

Chile

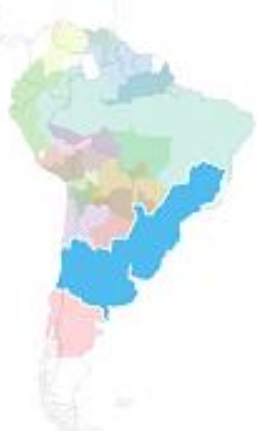

Amazonas

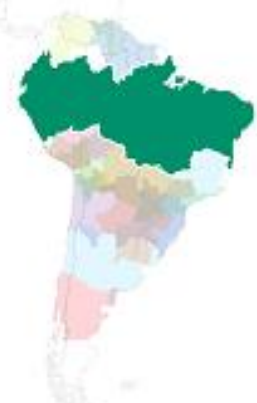

Hidrovia

Paraguai-Paraná

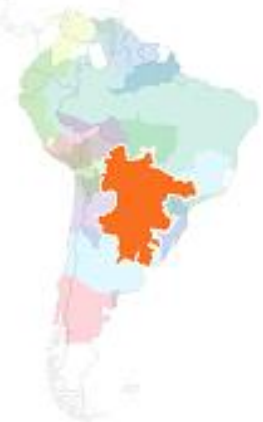

Peru-Brasil-Bolivia

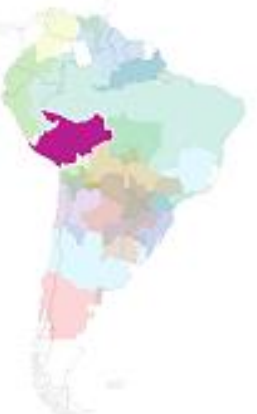

Capricórnio

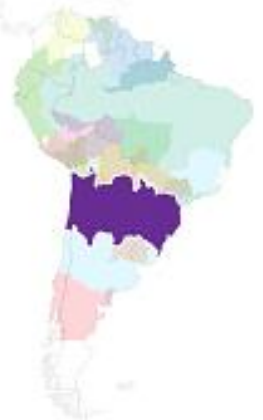

Interoceânico Central

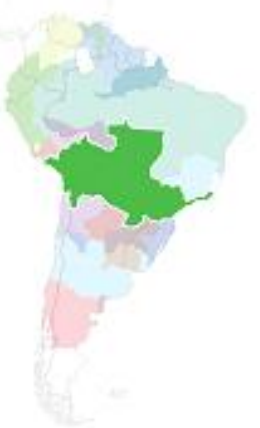

Do Sul 
O portifólio do COSIPLAN/IIRSA é composto pelo total de 562 projetos, que abrangem os setores de transportes, energia e comunicações (COSIPLAN, 2019). A quantidade de projetos varia de acordo com as discussões feitas pelos países sobre as prioridades da expansão das redes de infraestruturas e o impacto dos projetos para a integração do subcontinente. Ou seja, eles podem ser incluídos ou retirados do portfólio quando são finalizados ou se não estiverem enquadrados nos objetivos básicos de cada eixo.

A figura 2 mostra o total de projetos por EID. Os eixos MERCOSUL-Chile, Hidrovia Paraguai-Paraná e Capricórnio são os que possuem maior quantidade de projetos, pois a delimitação geográfica desses eixos abrange o interior da América do Sul, aonde as redes de transportes, energia e comunicações são rarefeitas. O processo de ocupação do território e a exploração dos recursos naturais ajudam a explicar essa conformação.

Figura 2. Total de projetos por Eixo de Integração e Desenvolvimento, 2019. Fonte dos dados: COSIPLAN/IIRSA, 2019. Elaborado pela autora

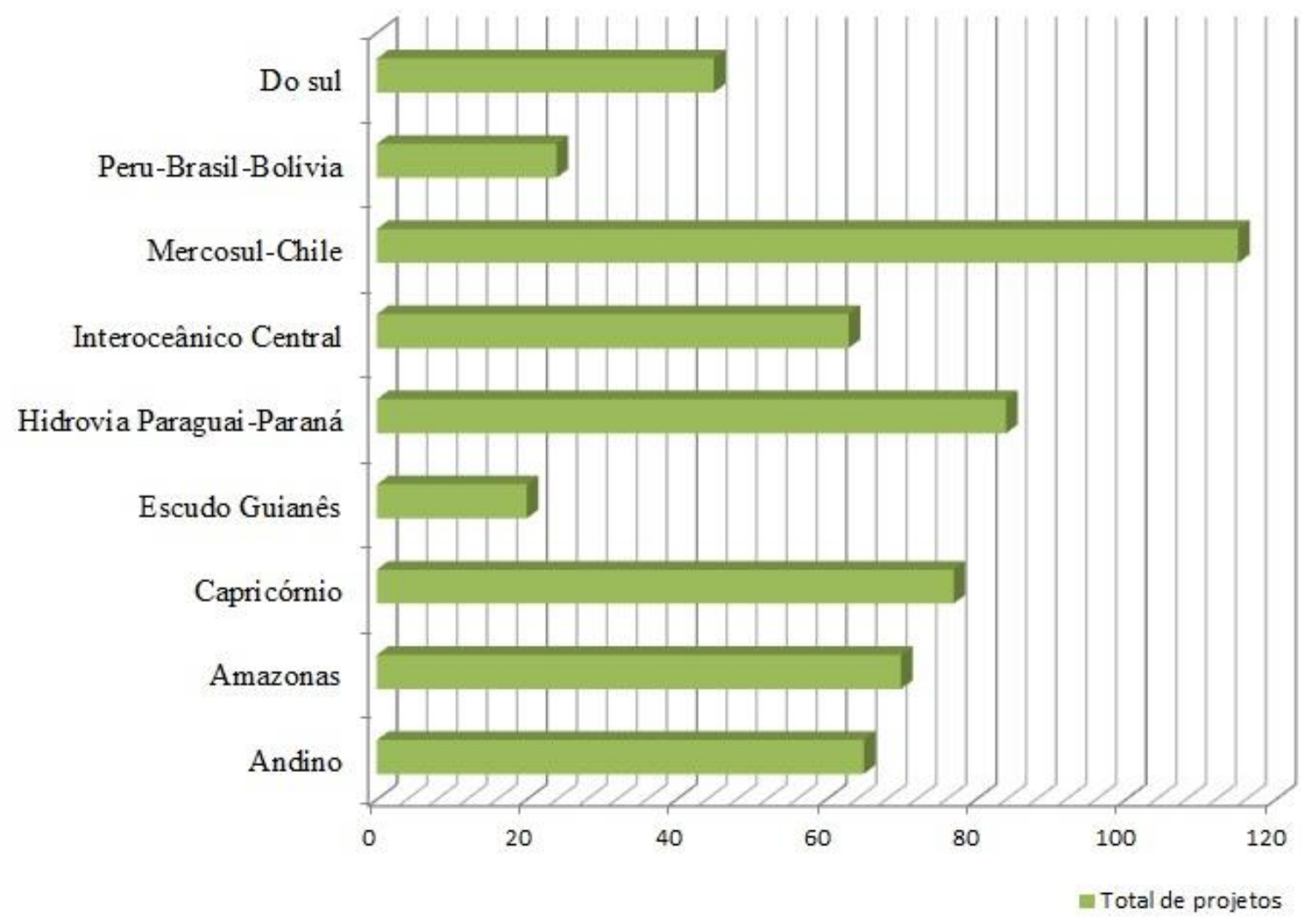

O desafio para a execução dos projetos elaborados para cada eixo é grande, pois o sistema de transportes no subcontinente possui inúmeros gargalos infraestruturais, dentre eles: conexões insuficientes entre os diferentes modais de transportes; estrangulamento de vias e pontes existentes; escassez e deterioração das ferrovias; dificuldades no estabelecimento de um sistema normativo e regulatório para a rede de transportes na América do Sul. 
Tal desafio torna-se ainda maior, pois a rede de infraestruturas é a base material para a circulação das mercadorias. Se essa base não corresponde à demanda dos fluxos do mercado internacional é inevitável que as mercadorias percam em competitividade. Quanto menor a competitividade, maior é a demanda por incorporação de novos conteúdos técnicos no território.

A demanda de fluxos a que estamos nos referindo é a circulação de commodities para a exportação, que é o principal grupo de mercadorias produzido pelos países sul-americanos, por conta da posição que ocupam na divisão territorial do trabalho. Por isso os projetos respondem com racionalidade às demandas de acumulação e circulação do capital. Portanto, as funções tradicionais do transporte nacional são modificadas, pois essas redes precisam atender às novas escalas e seus fluxos (BOUDOUIN, 2003). Em outras palavras,

O capital herda um mundo geográfico que já está diferenciado em complexos padrões espaciais. À medida em que a paisagem fica sob o domínio do capital, estes padrões são agrupados em uma hierarquia cada vez mais sistemática de escalas espaciais (SMITH, 1988, p. 196).

Majoritariamente, a maior quantidade de projetos de integração e investimento estimado pelo COSIPLAN/IIRSA são em projetos de infraestruturas de transportes, conforme indica a figura 3.

Cabe observar na comparação entre o número de projetos e o investimento estimado para cada subsetor que a quantidade de investimento estimado também depende da magnitude dos projetos, e não apenas da quantidade. Dois exemplos ilustrativos do Gráfico 02 são os projetos para o transporte ferroviário e para a geração de energia. Respectivamente, eles ocupam a terceira e a sexta posição em número de projetos, entretanto, em investimento estimado, a segunda e a terceira.

No caso do transporte ferroviário, a falta de conectividade da rede existente, o tamanho divergente das bitolas e a priorização do transporte rodoviário fez com que a rede ferroviária se tornasse inadequada e obsoleta, necessitando, portanto, de alto investimento para operar de forma eficiente na circulação de mercadorias.

Embora o modal rodoviário tenha sido tomado como a prioridade na rede de infraestruturas dos países sul-americanos, a partir da política de substituição das importações criada pela CEPAL, o estrangulamento das vias e a intensificação do tráfego, aliados à falta de conectividade da rede explicam o primeiro lugar no total de investimento estimado e no número de projetos (indicado na figura 3). 
Figura 3. Total de projetos e investimento estimado por setor dos EIDs, 2019. Fonte dos dados: COSIPLAN, 2019. Elaborado pela autora

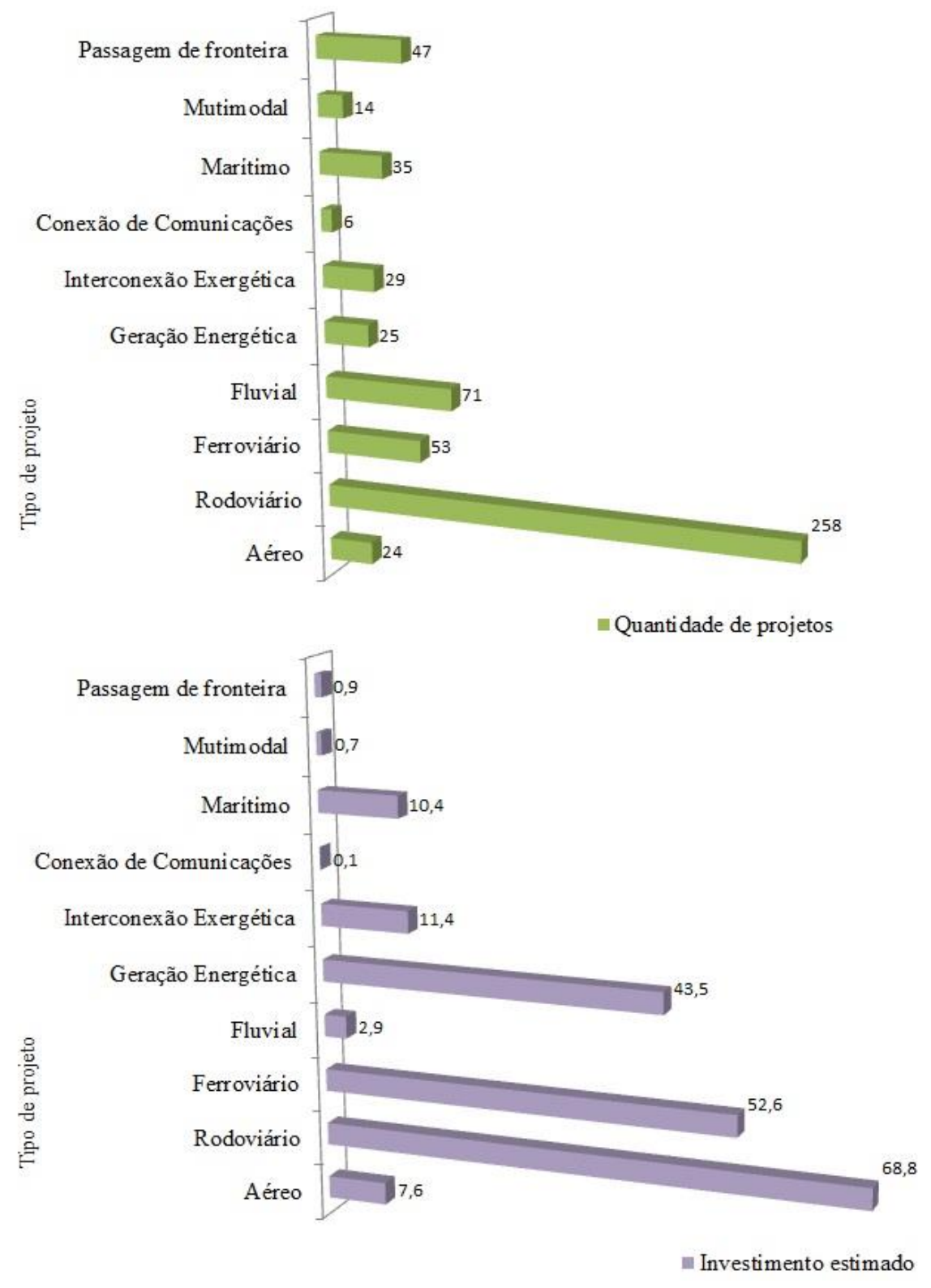

No portifólio do COSIPLAN/IIRSA existe uma Agenda de Projetos Prioritários de Integração (API). A prioridade é definida de acordo com as demandas nacionais e o compromisso assumido para a sua execução, além disso, o projeto deve ter um alcançe regional e transfronteiriço, estar de acordo com o perfil de "desenvolvimento sustentável" e ter impactos na integração regional (COSIPLAN, 2013). Ao todo, em 2016, 31 projetos compunham a API do COSIPLAN/IIRSA. A figura 4 mostra o número de projetos por eixo e o total de investimento estimado (em bilhões de dólares). 
Figura 4. Investimento estimado (em bilhões de dólares) e número de projetos da API por eixo em 2016. Fonte dos dados: COSIPLAN, 2016 b. Elaborado pela autora

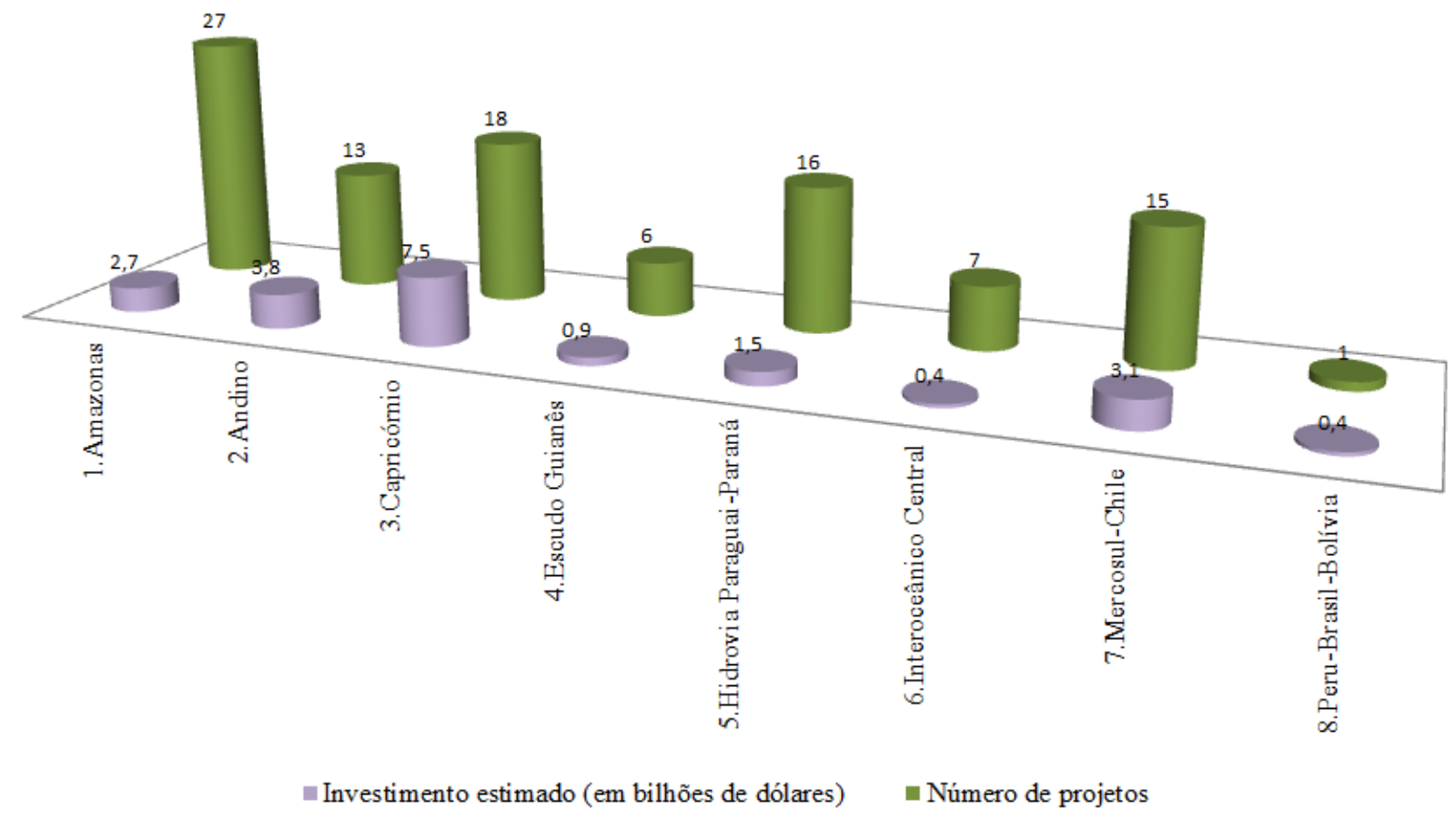

A partir da figura 4, percebemos que o Eixo de Capricórnio (analisado no próximo tópico do artigo) possui o maior volume de investimento estimado. Isso ocorre devido à deterioração das infraestruturas existentes, pela dispersão da rede de transportes e sua demanda por conexão para melhor atender os fluxos, além da necessidade de estudos técnicos e adaptações para a execução dos mesmos. Comparativamente, outros eixos, como o Amazonas, a Hidrovia Paraguai-Paraná e o Mercosul-Chile, apesar de possuir quantidade de projetos maior ou similiar ao Eixo de Capricórnio, demandam um investimento estimado menor. Outro ponto que contribui para o valor de investimento estimado do Eixo de Capricórnio na API é a quantidade de projetos relacionados à rede ferroviária.

Diante da dimensão dos investimentos estimados no portifólio do COSIPLAN/IIRSA, uma questão fundamental deve ser considerada: Quem financia os projetos?

O COSIPLAN/IIRSA não conta com uma fonte de financiamento específica, portanto, cabe a cada país financiar os projetos que serão executados em seu território. Porém, nem todos contam com as mesmas possibilidades de investimento em infraestruturas. Diante disso, a questão financeira se impõe como um impedimento para a execução dos projetos em países como a Bolívia e o Paraguai, por exemplo.

A figura 5, mostra o percentual de composição de investimentos estimados para os projetos da API em 2016, considerando o total de projetos em cada país. A demanda de investimento é maior para Paraguai (20\%), seguido por Argentina (15\%), Brasil (13\%) e Peru (12\%). 
Figura 5. Composição de investimentos estimados da API por país, 2016. Fonte dos dados: COSIPLAN, 2016 b. Elaborado pela autora

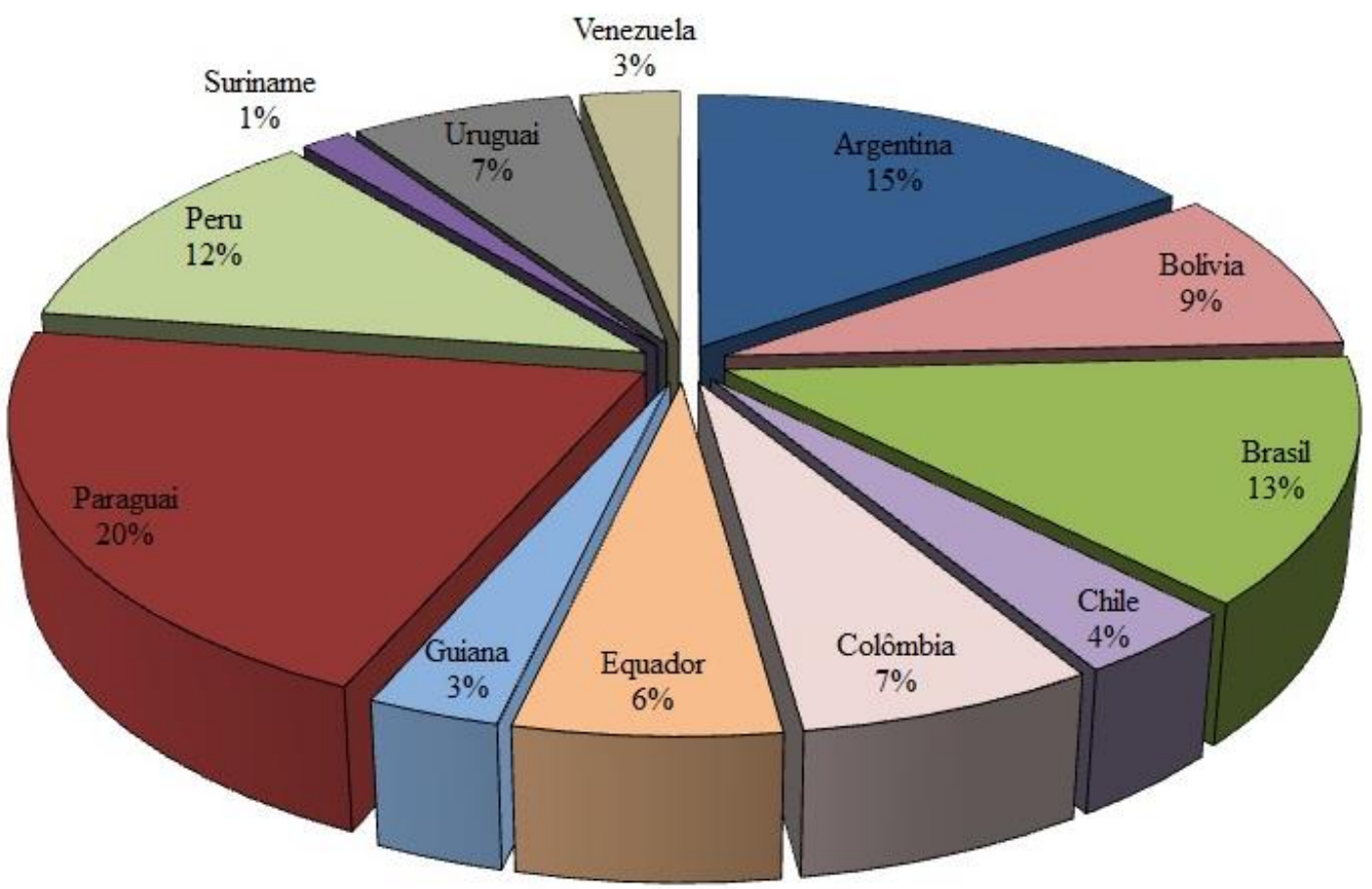

O caso do Paraguai é um dos mais problemáticos em relação à demanda por investimento em projetos, pois o país não dispõe de condições para arcar com os custos necessários. Além disso, boa parte dos projetos elaborados para execução no território paraguaio teriam benefícios maiores para os vizinhos, por conta da localização geográfica do país e as possibilidades de conexão entre diferentes redes (OLIVEIRA CRUZ, 2017).

O problema poderia ser minimizado caso o COSIPLAN/IIRSA tivesse um sistema de financiamento próprio, assim como o Fundo para a Convergência Estrutural do MERCOSUL (FOCEM). Outro ponto a ser considerado seria a divisão dos custos pelos países beneficiários de um projeto, mesmo que sua execução ocorresse fora de seus limites geográficos.

Embora os países sejam os principais responsáveis pelo investimento nos projetos de infraestruturas, três organizações financeiras também colaboram ativamente com o COSIPLAN/IIRSA. São elas: Banco Interamericano de Desenvolvimento (BID), Corporação Andina de Fomento (CAF) e o Fundo Financeiro para o Desenvolvimento da Bacia do Prata (FONPLATA). Porém a atuação dessas organizações está relacionada ao apoio financeiro para elaboração de estudos e relatórios técnicos, fóruns e reuniões.

Alguns países contam com financiadores internos, como é o caso do Banco Nacional de Desenvolvimento Econômico e Social (BNDES), no Brasil. O BNDES financia também as construtoras e empresas brasileiras que atuam em projetos no exterior, sobretudo nos setores de energia e transportes, na construção de gasodutos, rodovias e obras portuárias (ANTUNES, 2007). 


\section{O Eixo de Capricórnio}

O Eixo de Capricórnio é composto por Argentina, Brasil, Bolívia, Paraguai e Chile. Atualmente, o portifólio deste eixo possui 77 projetos, com o investimento estimado de 15 bilhões de dólares (COSIPLAN, 2019). A maior parte dos projetos é destinado ao modal rodoviário (42 projetos), seguido pelo modal ferroviário (14 projetos).

Em 2016, os projetos foram distribuídos em 11 projetos binacionais e 70 projetos nacionais, cuja localização é demonstrada no mapa 01 . Os projetos nacionais foram distribuídos da seguinte forma: 42 projetos argentinos; 21 projetos paraguaios; 18 projetos chilenos; 8 projetos brasileiros; 3 projetos bolivianos (COSIPLAN, 2016), com a predominância do financiamento feito pelo setor público, cuja soma foi de 14,6 bilhões de dólares (COSIPLAN, 2016).

A justificativa para a composição da área de influência do eixo é a necessidade de atrair novos fluxos internacionais através da expansão da rede de transportes (atualmente limitada e dispersa). A área de influência do Eixo de Capricórnio corresponde a 15,3\% do território sul-americano, 13,2\% da população e 574 bilhões de dólares do PIB da América do Sul (COSIPLAN, 2016).

34\% dos fluxos do eixo são voltados à exportação, dos quais se destacam: cobre refinado, soja, petróleo, mineral de cobre e seus concentrados, e mineral de ferro e seus concentrados (OLIVEIRA CRUZ, 2017). A fim de tornar mais fluida à circulação destes fluxos de mercadorias no território, juntamente com os fluxos de grãos e carnes, a proposta de conectividade entre os portos dos oceanos Pacífico e Atlântico possuem destaque.

Lamoso (2011), explica a relação entre a produção de commodities no centro-oeste brasileiro e a criação de uma rede técnica de transportes, a fim de conectar as áreas produtoras aos principais mercados internacionais. Vemos a partir deste exemplo, as transformações na rede de transportes, e consequentemente, no território, estimuladas pela exportação. O mesmo tem sido observado em relação aos demais países sul-americanos e o perfil dos projetos internacionais de integração, presentes no portifólio do COSIPLAN/IIRSA.

Embora alguns projetos mencionem a importância das infraestruturas para a circulação de pessoas, o foco é a circulação de mercadorias. Esses novos objetos técnicos são projetados com um fim específico, cuja finalidade faz parte de um sistema de objetos, conforme Santos (2008), no intuito de facilitar a circulação e acumulação do capital.

No caso do Eixo de Capricórnio, o Corredor Ferroviário Paranaguá-Antofagasta é o principal projeto em extensão e investimento estimado. Para Blanco (2015, p. 26), este tipo de projeto é feito para "garantizar la fluidez entre los extremos y puntos significativos, que niegan las necesidades en las sucesivas escalas locales de circulación articuladas con el corredor". A proposta é a integração de nove estados, departamentos e províncias, com uma área de influência de 769.985 km², que somam um PIB de 165,5 bilhões de dólares, além da interligação dos portos 
chilenos de Antofagasta e Mejillones, ao porto brasileiro de Paranaguá, com uma conexão intermodal com a hidrovia Paraguai-Paraná (COSIPLAN, 2017).

Os desafios específicos para a execução do projeto estão relacionados às características da rede ferroviária de cada país (Argentina, Brasil, Bolívia, Paraguai e Chile). A principal dificuldade é o Paraguai, cujo sistema ferroviário está totalmente inativo (COSIPLAN, 2017).

Além do corredor bioceânico, outros quatro projetos compõem a API do Eixo de Capricórnio: Construção da ponte binacional Salvador Mazza-Yacuiba e Centro de Fronteira entre Bolívia e Argentina; Conexão Oeste Argentina-Bolívia; Linha de transmissão 500 KV (Itaipu-Asunción-Yacyretá) entre Brasil e Paraguai; Conexão viária Foz-Ciudad del Este-Asunción-Clorinda entre Argentina, Brasil e Paraguai.

Dentre as críticas feitas ao processo de regionalização proposto pelo COSIPLAN/IIRSA para o Eixo de Capricórnio destacam-se os impactos ambientais. Os impactos são causados por dificuldades técnicas em transpor cordilheiras, florestas, áreas de reserva e conservação, regiões ocupadas por populações originárias, áreas com ocorrência de inundações, atividade vulcânica, terremotos e tsunamis (OLIVEIRA CRUZ, 2017). No território chileno, paraguaio e boliviano, a existência de populações originárias e características da geografia física local são vistas como desafios para a execução de projetos no eixo.

\section{CONSIDERAÇÕES FINAIS}

Conforme discutimos ao longo do artigo, existe uma complexa relação entre fixos e fluxos, cuja demanda é a garantia de fluidez e eficácia na circulação e acumulação de capital. Embora o recorte escolhido tenha sido a América do Sul, cabe ressaltar que essa não é uma demanda apenas subcontinental, mas abrange todo o mundo globalizado, imputando aos lugares a lógica simultânea de integração-desintegração.

Tal lógica reflete no perfil dos projetos de integração regional, elaborados pelo COSIPLAN/IIRSA, no intuito de garantir maior competitividade da produção de mercadorias sul-americanas no contexto internacional. No entanto, essa garantia reforça a posição que os países do subcontinente ocupam na divisão territorial do trabalho.

Mesmo com a mudança no perfil político regional a partir de 2003, concluímos que não houve uma tentativa de reverter a perversidade da lógica simultânea de integração-desintegração. Ao contrário, ela foi aprofundada, no mesmo ritmo em que a cooperação sul-sul ganhou destaque.

Este quadro tornou-se ainda mais complexo, pois, atualmente, vivemos um novo contexto de incertezas no subcontinente, no qual as iniciativas de integração regional não possuem a mesma projeção e o destaque de outrora. O impeachment da ex-presidente Dilma Rousseff, no Brasil, e a eleição do presidente Maurício Macri, na Argentina, iniciaram uma nova mudança no cenário político regional, contrária àquela que corroborou para a 
criação da UNASUL. O grande retrocesso veio com a eleição de Jair Bolsonaro e a criação do PROSUL em março de 2019 em substituição à UNASUL, inaugurando um novo começo para a integração regional, feita de forma perversa, excludente e ideológica, baseada na manutenção da dependência regional em relação aos países do centro do sistema capitalista (OLIVEIRA CRUZ, 2019).

Por outro lado, para o desenvolvimento capitalista e atuação dos bancos e capitais transacionais, o aprimoramento da base material das redes com novos conteúdos técnicos é elementar. Diante disso, o enfraquecimento do diálogo regional possibilita a incorporação desses novos conteúdos técnicos de forma ainda mais perversa, reforçando os pontos de exclusão e as contradições.

A proposta de expansão das redes técnicas segue a lógica de homogeneização das redes globais, cujo contraponto são as resistências quanto ao direito das populações originárias, e o questionamento da postura adotada pelas empresas e pelos Estados nacionais quanto à relação sociedade-natureza. As tensões inerentes às dinâmicas territoriais contemporâneas expressam as intencionalidades no processo de integração, bem como sua complexidade política e econômica.

Por fim, não deixamos de reconhecer a importância representada pelo COSIPLAN/IIRSA e seu respectivo espaço de diálogo, criado para debater as propostas de expansão das redes de infraestruturas. Pelo contrário, concluímos que embora o debate necessitasse ser aprimorado, sobretudo, em relação ao financiamento dos investimentos e aos impactos sociais e ambientais, foi uma grande perda o Brasil ter se retirado das discussões. Procuramos discutir, no entanto, as intencionalidades e os objetivos dos projetos de integração regional, destacando a forma como são apropriados pela lógica de desenvolvimento e acumulação aos moldes contraditórios do capitalismo flexível.

\section{REFERÊNCIAS}

ALBUQUERQUE, E. S. 80 anos da obra Projeção Continental do Brasil, de Mário Travassos. In: Revista do Departamento de Geografia - USP, vol. 29, 2015, p. 59-78.

ANTUNES, A. J. C. Infraestrutura na América do Sul: situação atual, necessidades e complementaridades possíveis com o Brasil. Brasília: CEPAL, 2007.

ARROYO, M. Redes e circulação no uso e controle do território. In: ARROYO, M; CRUZ, R. C. A. (orgs). Território e circulação. A dinâmica contraditória da globalização. São Paulo: Anablume Geografias, 2015, p. 37-50.

ARROYO, M. MERCOSUL: novo território ou ampliação de velhas tendências? In: SCARLATO, F. C.; SANTOS, M.; SOUZA, M. A. A. de; ARROYO, M. (Org.). O novo mapa do mundo: globalização e espaço latino-americano. São Paulo: Hucitec-ANPUR, 2002, p. $122-131$.

BECKER, B. K. A geopolítica na virada do milênio: logística e desenvolvimento sustentável. In: CASTRO, I. E; GOMES, P. C. da C; CORRÊA, R. L (orgs). Geografia: conceitos e temas. 2. ed. Rio de Janeiro: Bertrand Brasil, 2000, p. 271-308

BLANCO, J. Territorio, circulación y redes: articulaciones y tensiones. In: ARROYO, M; CRUZ, R. C. A (orgs). Território e circulação: a dinâmica contraditória da globalização. São Paulo: FAPESP, 2015, p. 15-36. 
BOUDOUIN, T. Territórios produtivos, empresas multinacionais e Estados na logística mundial. In: MONIÉ, F; SILVA, G (orgs). A mobilização produtiva dos territórios - instituições e logística no desenvolvimento local. Rio de Janeiro: DP\&A, 2003, p. 25-42.

CASTELLS, M. A sociedade em rede. 8. ed. São Paulo: Paz e Terra, 1999.

CASTILLO, R. A. Agricultura globalizada e logística nos cerrados brasileiros. In: SILVEIRA, M. R. Circulação, transporte e logística: diferentes perspectivas. São Paulo: Outras Expressões, 2011, p. 331-354.

CORRÊA, R. L. Interações espaciais. In: CASTRO, I. E (org). Explorações geográficas. Rio de Janeiro: Bertrand Brasil, 1997, p. 279-318. CORRÊA, R. L. Trajetórias geográficas. 2. ed. Rio de Janeiro: Bertrand Brasil, 2001.

COSIPLAN. Sistema de información de proyectos. 2019. Disponível em: < http://www.iirsa.org/proyectos/visualizaciones/mapa/>, acesso em 04 de março de 2019.

COSIPLAN. Insumos para elaborar uma estrategia que facilite la integración ferroviaria de Suramérica. Montevideo: Ministério de transportes e obras públicas, 2017.

COSIPLAN. Cartera de proyectos 2016. Foro Técnico IIRSA. Secretaria CCT COSIPLAN/IIRSA, 2016.

COSIPLAN. Agenda de proyectos prioritarios de integración 2016. Secretaria CCT COSIPLAN/IIRSA, 2016 (b).

COSIPLAN. Agenda de proyectos prioritarios de integración. Santiago: COSIPLAN, 2013.

DIAS, L. C. Redes - emergência e organização. In: CASTRO, I. E; GOMES, P. C.C; CORRÊA, R. L (orgs). Geografia: conceitos e temas. 2. ed. Rio de Janeiro: Bertrand Brasil, 2000, p. 141-164.

EGLER, C. A. G. MERCOSUL: um território em construção? Disponível em:

<http://cienciaecultura.bvs.br/pdf/cic/v58n1/a13v58n1.pdf>. Acesso em 29 de junho de 2014.

HAESBAERT, R. O mito da desterritorialização: Do “fim dos territórios” à multiterritorialidade. Rio de Janeiro: Bertrand Brasil, 2004.

LIMA, M. R. S. de. Relações interamericanas: a nova agenda sul-americana e o Brasil. In: Revista Lua Nova. São Paulo, 2013, p. 167201.

LAMOSO, L. Fluxos e redes técnicas no comércio de minério no território brasileiro. In: SILVEIRA, M. R. Circulação, transporte e logística: diferentes perspectivas. São Paulo: Outras Expressões, 2011, p. 355-377.

LEFEBVRE, H. O direito à cidade. São Paulo: Centauro, 2001.

OLIVEIRA CRUZ, D. A. M. Geopolítica e integração regional: uma análise dos projetos de integração regional de transportes entre Brasil e Paraguai. Tese. Doutorado em Geografia. 133 f. 2017. Presidente Prudente: Universidade Estadual Paulista.

OLIVEIRA CRUZ, D. A. M. Integração regional sul-americana e a intersecção entre geopolítica e geoeconomia: reflexões sobre a UNASUL e o MERCOSUL. In: ALVES, D. F (et al.). A dimensão política no espaço: conflitos e desigualdades territoriais na sociedade contemporânea. Alfenas: Editora Universidade Federal de Alfenas, 2019, p. 205-221.

PORTO-GONÇALVES, C. W.; QUENTAL, P. A. Colonialidade do poder e os desafios da integração regional na América Latina. In: Revista Polis, n.31, 2012, p. 1-28. Disponível em: polis.revues.org/3749. Acesso em 25 de setembro de 2015.

RAFFESTIN, C. Por uma geografia do poder. São Paulo: Editora Ática, 1993.

SANAHUJA, J. A. La construcción de uma región: Suramérica y el regionalismo posliberal. In: CIENFUEGOS, M; SANAHUJA, J. A (org.). Una región en construcción. Unasur y la integración en América del Sur. Barcelona: Edicions Bellaterra, 2010, p. 87-134.

SANTOS, MILTON. A natureza do espaço: técnica e tempo, razão e emoção. 4. ed. São Paulo: Edusp, 2008

SMITH, Neil. Desenvolvimento Desigual. Rio de Janeiro: Bertrand Brasil, 1988.

SOUZA, A. de O. A política de transporte no Governo Fernando Henrique Cardoso: o exemplo do modal ferroviário no Estado do Mato Grosso do Sul. In: SILVEIRA, M. R. (org). Circulação, transporte e logística. Diferentes perspectivas. São Paulo: Outras expressões, 2011, p. 403-426.

VIGEVANI, T; RAMANZINI JÚNIOR, H. Autonomia, integração regional e política externa brasileira: MERCOSUL e UNASUL. In: Revista de Ciências Sociais. Rio de Janeiro. vol. 57. n. 2, 2014, p. 517-552. 